Finisterra, XXXV, 70, 2000, pp. 133-135

\title{
MODERNIZAÇÃO DA GESTÃO URBANA ${ }^{1}$
}

Carlos Nunes Silva 2

O tema escolhido por Catherine Soldano para a sua dissertação de doutoramento é hoje uma das questões fundamentais nos estudos sobre o poder local. A sua importância radica no facto de o poder local, enquanto micro-sistema político, permitir testar as hipóteses que a autora considerou, o que seria mais difícil noutros níveis da organização política.

A tese está estruturada em 7 capítulos com um total de 394 páginas. No capítulo 1 (p. 7-38) C. Soldano analisa a transformação da administração municipal em França nas últimas duas décadas e meia. Apresenta a evolução geral do modelo de governo municipal no período de 1970-90, considerando várias etapas: politização dos governos municipais (1971-82), descentralização e reforço das competências do governo local (1982-84) e processo de liberalização nos anos 90, que envolveu a emergência de um novo modo de governo. No capítulo 2 (p. 39-71), a autora apresenta a problemática e os objectivos. Faz uma revisão da bibliografia, sobretudo da francesa, acerca do modelo tradicional (weberiano) e do questionamento feito ao mesmo nos anos 70 , seguido pela emergência do «management model». O objectivo foi o de determinar se este último modelo é ou não responsável pela recomposição das funções políticas e administrativas. Soldano conclui que «management» não deve ser considerado equivalente à função administrativa mas como uma actividade de interface entre a função política e a função administrativa. Faz o contraste entre o modelo weberiano tradicional da gestão municipal, que designa por «bureaucratie exécutante», e o novo modelo de gestão municipal, que designa por "gestion managériale». A tese principal é que o modelo weberiano cedeu lugar a novas formas de relação entre políticos e técnicos como condição para a melhoria da eficiência e da eficácia, em substituição da antiga

\footnotetext{
1 Soldano, Catherine (1999) - La modernisation des mairies. De la bureaucratie exécutante au gouvernment managérial. Université de Toulouse Le Mirail - Département de Sociologie. Toulouse. Vol. I (200 p.) e Vol. II (194 p.). Tese de doutoramento orientada por Jean-Yves Nevers do CERTOP -CNRS.

2 Professor Auxiliar da Universidade de Lisboa. Investigador do Centro de Estudos Geográficos. E-mail: carlos.silva@fc.ul.pt
} 
associação entre o maire e o secretário-geral. No capítulo 3 (p. 72-103), a autora trata da metodologia de investigação e dos casos de estudo. A escolha dos três casos de estudo seguiu três critérios: (i) serem representativos de municípios de média dimensão e de municípios suburbanos, (ii) a situação política e (iii) a existência de mudanças organizacionais significativas. Nos três capítulos seguintes, C. Soldano apresenta a investigação realizada nos três casos de estudo (Cap. 4, o município de Albi, p. 104-200; Cap. 5, o município de Castres, p. 201-266; Cap. 6, o município de Blagnac, p. 267-354). No Cap. 7, apresenta uma síntese e tenta integrar os casos de estudo no quadro teórico desenvolvido nos capítulos iniciais.

O objectivo da investigação é a análise das condições e dos efeitos das mudanças nos modos de governo municipal, baseado nos três casos de estudo, municípios de dimensão média no Sul de França, em dois contextos diferentes (1970-85 e anos 90). A questão de investigação foi claramente definida: quais foram as mudanças na organização e funcionamento dos municípios urbanos nos anos 80 e 90? Relativamente aos aspectos formais, o estudo de C. Soldano está bem estruturado. Começa por apresentar a questão de partida seguindo depois os passos próprios do procedimento científico - problemática, modelo de investigação, análise e conclusão.

A autora procura a cada passo identificar as mudanças em direcção a um novo modo de governação urbana. Dois momentos e dois paradigmas são por ela considerados: os anos 70, quando o modelo tradicional de administração local, designado por «bureaucratie exécutante», era dominante e o começo dos anos 90, caracterizado pelas ideias do «New Public Management». No primeiro caso, a característica principal é a separação entre o nível de decisão política e o nível de execução. No segundo paradigma, a característica principal é a politização do nível de execução e a mistura de ambos, a certos níveis. A tese principal que a autora propõe é que o processo de «managerialisation» do governo municipal, desenvolvido sobretudo nas últimas duas décadas, foi responsável pela mudança no modelo de governo municipal em França. A principal contribuição é, por isso, a identificação das condições em que as novas práticas, designadas na bibliografia como "New Public Management», foram adoptadas em municípios franceses.

As diferenças entre os três casos de estudo ((i) Albi, um município governado pela Union de la Gauche, entre 1971 e 1995; (ii) Castres, um município em que o poder mudou duas vezes no período estudado; (iii) Blagnac, um município suburbano, em que o «new public management» foi posto em prática por um partido político de direita) limitaram a abordagem comparativa e, por isso, a autora considerou-os como sendo representativos de situações específicas («situações-tipo»). A metodologia do trabalho de campo baseou-se exclusivamente em técnicas qualitativas de investigação: incluiu um número significativo de entrevistas, a líderes políticos, a técnicos e a representantes 
dos sindicatos e utilizou os documentos internos dos municípios. Estudou os projectos de reforma em cada um dos municípios nos períodos em causa, os processos de transformação, as medidas adoptadas e os contextos em que as decisões foram tomadas. Em suma, Soldano estudou a acção voluntária de diferentes actores na organização municipal através de quatro questões: Porque mudou? Como? Com quem? Com que resultados?

No último capítulo, a autora faz um balanço destes processos de mudança organizacional. Compara os diferentes tipos de processos de modernização municipal nas duas conjunturas diferentes. No primeiro período houve um processo de modernização, em parte associado às mudanças no ambiente externo e ao confronto entre esquerda e direita, mas em que a classe política conseguiu manter o controlo global do processo de decisão política interno. No segundo período considerado, os anos 90, o principal objectivo foi a implementação de um sistema de gestão municipal mais eficiente, tendo-se verificado uma perda parcial de controlo do processo de decisão por parte da classe política local.

Não obstante o rigor e o interesse da investigação desenvolvida por Soldano, o produto final apresenta algumas limitações. Por exemplo, a bibliografia está demasiado centrada em autores franceses, representando os não franceses menos de $10 \%$ em 122 referências bibliográficas utilizadas. Há um vasto campo da bibliografia anglo-saxónica sobre este tema que foi ignorado e com certeza que perspectivas interessantes poderiam ter sido consideradas se tivessem sido utilizadas. Por outro lado, outras técnicas de investigação poderiam ter sido aplicadas com vantagem nos resultados finais. Vale também a pena mencionar a falta de uma avaliação da percepção destas mudanças organizacionais e dos seus efeitos por parte da população. Como é que as avaliam? Como foram consideradas? Não há, em suma, uma avaliação global destas mudanças em termos de eficiência, eficácia e impacte. Por fim, teria sido útil incluir em anexo os questionários e os guiões das entrevistas que foram utilizados no trabalho de campo.

Mas é, sem dúvida, um trabalho de investigação consistente no sentido em que tem uma (hipó)tese claramente elaborada e que é submetida a um teste ao longo de todo o processo de pesquisa, seguindo as regras apropriadas do procedimento científico. O trabalho empírico é sério e toda a investigação foi cuidadosamente desenhada. Todos os aspectos formais de um trabalho deste tipo foram respeitados. A formulação da(s) (hipó)tese(s) no início de cada capítulo e, na conclusão, a referência à verificação ou não da(s) mesma(s), a definição da problemática e de um quadro teórico claro na parte inicial do trabalho são também aspectos a reter. Em conclusão, o trabalho de Catherine Soldano é um importante contributo para o estudo do governo local e das reformas organizacionais ao nível municipal e será certamente uma referência para os trabalhos seguintes sobre as mudanças na gestão urbana. 